\title{
Tracking User Location dengan Menggunakan Geotagging pada Metadata Photo
}

\author{
I Wayan Ardiyasa ${ }^{1}$, Pande Putu Gede Putra Pertama² \\ (STMIK) STIKOM Bali ${ }^{1,2}$ \\ ardi@stikom-bali.ac.id'1, putrapertama@stikom-bali.ac.id²
}

\begin{abstract}
Abstrak - Adanya teknologi menjadikan akses informasi tidak ada batas antara jarak, ruang dan waktu. Selain akses informasi, teknologi menjadikan pengguna lebih mudah didalam melakukan komunikasi dengan menggunakan ponsel. Ponsel merupakan teknologi telepon genggam yang bisa digunakan utnuk layanan telekomunikasi. Selain untuk komunikasi, ponsel bisa digunakan untuk browsing, chatting, swafoto dan lain sebagainya. Teknologi ponsel atau smartphone banyak memiliki fitur salah satunya adalah GPS. Teknologi GPS memungkinkan pengguna untuk mengetahui lokasi dan bisa digunakan sebagai peta digital atau istilahnya adalah Map Info. Sinkronisasi antara teknologi GPS dengan kamera pada ponsel memungkinkan pengguna menghasilkan photo yang bisa digunakan untuk mengetahui lokasi foto dari pengguna, ini dikarenakan sinkorniasasinya fitur GPS dengan kamera yang menyimpan informasi latitude dan longitude kedalam photo atau disebut dengan geotagging. Pada penelitian ini, membuat aplikasi untuk melakukan tracking user location, yang mampu mengetahui keberadaan atau lokasi user dengan menggunakan media photo. Dihasilkannya aplikasi tracking user location ini dapat membantu para pihak-pihat terkait seperti halnya masyarakat umum, akademisi dan digital forensic guna mengetahui lokasi pengguna
\end{abstract}

Kata kunci: Geotagging, Ponsel, Lokasi, GPS.

\section{Latar Belakang}

Kebutuhan akan teknologi meningkat seiring dengan tingginya akses informasi secara digital. Selain itu teknologi informasi digunakan untuk membantu pengguna didalam memecahkan permasalahan dan pencarian solusi sehingga pengguna sangat terbantukan dengan kehadiran teknologi seperti monitoring kondisi cuaca, layanan telekomunikasi dan komunikasi video call serta mengetahui lokasi pengguna dari media photo yang diambil dengan menggunakan ponsel. Geotagging adalah fitur yang terdapat didalam kamera ponsel yang tersinkronisasi dengan fitur GPS yang bisa memberikan informasi secara realtime. Teknologi Ponsel saat ini sudah dilengkapi dengan kamera dan fitur GPS yang digunakan oleh pengguna untuk menghasilkan sebuah photo yang bisa menyimpan data geotagging yang didalamnya terdapat informasi latitude dan longitude. Banyak ponsel yang dilengkapi dengan fitur GPS yang dapat menambahkan informasi lokasi ke dalam sebuah photo atau disebut dengan Exif secara otomatis sehingga lokasi foto tersebut dapat ditampilkan ke dalam peta. (Zaenudin, Sugiantoro, \& Prayudi, 2018)

Tracking user location dengan menggunakan metadata photo merupakan aplikasi yang menampilkan informasi tentang lokasi pengguna. Aplikasi ini digunakan untuk melakukan investigasi serta melacak lokasi pengguna dari metadata geotagging yang diekstrak dari sebuah photo. Untuk menampilkan informasi lokasi pengguna, aplikasi tracking user location menggunakan metadata geotagging photo dimana informasi tersebut didapatkan dari titik kordinat GPS pada sebuah ponsel yang memiliki fitur GPS dan fitur save location info dengan kondisi aktif. Dari titik kordinat GPS dan geotag itu, informasi latitude dan longitude ditambahkan berupa marker kedalam metadata file photo yang bisa ditampilkan kedalam bentuk sebuah map. Hasil akhir penelitian ini adalah Aplikasi berbasis web yang bisa menampilkan lokasi user. Tujuan penelitian ini adalah membantu didalam melakukan pencarian atau investigasi dan pembuktian untuk mengetahui lokasi pengguna bagi pihak-pihak terkait seperti kepolisisan dan tim investigasi digital forensic dari sebuah media digital yaitu photo.

\section{Kajian Pustaka}

\section{A. Metadata}

Metadata adalah informasi yang berisi tentang karakteristik data. Metadata berisi informasi yang menggambarkan karakteristik data, seperti konten, kualitas, kondisi, dan cara memperolehnya. Metadata dibagi menjadi tiga jenis yaitu deskriptif metadata, administratif metadata dan metadata struktural. Deskriptif 
Metadata adalah Data yang dapat mengidentifikasi sumber informasi sehingga dapat digunakan untuk mempermudah proses penemuan dan seleksi. Cakupan didalamnya adalah penulis, judul, tahun publikasi, subjek atau header kata kunci dan informasi lainnya yang proses pengisiannya sama dengan katalog tradisional. Sedangkan Metadata Administratif adalah Data yang tidak hanya dapat mengidentifikasi sumber informasi tetapi juga bagaimana ia dikelola. Ruang lingkup data ini sama dengan data deskriptif hanya dengan pembuat data, waktu pembuatan, jenis file, data teknis lainnya. Selain itu, data ini juga berisi informasi tentang hak akses, hak kekayaan intelektual, penyimpanan dan pelestarian sumber daya informasi. Metadata Struktural adalah Data yang dapat membuat antara data terkait dapat dikaitkan satu sama lain. Lebih eksplisit, metadata ini digunakan untuk menentukan hubungan antara file fisik dan halaman, halaman dan bab dan bab dengan buku sebagai produk akhir.(Zaenudin et al., 2018)

\section{B. GPS (Global Positioning System)}

Global Positioning System (GPS) adalah sistem navigasi berbasis satelit yang dibuat setidaknya dengan 24 satelit. Penerima GPS mengukur jarak dengan menghitung waktu yang dibutuhkan untuk menerima data yang dikirim oleh tiap satelit. Dengan pengukuran jarak oleh beberapa satelit, penerima GPS dapat menentukan dimana lokasi pengguna selanjutnya digunakan untuk mengukur jarak, memetakan wilayah, atau mencari rute.(Nur, Handayani, \& Sudarsa, 2017) Pada ponsel yang memiliki kamera bisa disinkronisasikan dengan menggunakan fitur GPS, sehingga menghasilkan photo yang memiliki informasi geotagging. Satelit GPS menggunakan energi matahari, memiliki baterai cadangan untuk menjaga agar mampu beroperasi. Keistimewaan GPS adalah mampu bekerja dalam berbagai kondisi cuaca, siang atau malam. Keakuratan sebuah perangkat GPS bisa mencapai 15 meter, bahkan model terbaru yang dilengkapi teknologi Wide Area Augmentation System (WAAS) keakuratannya sampai 3 meter. (Bandung, n.d.)

\section{Geotagging Photo}

Geotagging merupakan sinkronisasi antara fitur kamera dengan fitur GPS dalam proses penambahan informasi data GPS seperti Latitude dan Longitude kedalam sebuah photo digital. Teknologi ponsel saat ini sudah memiliki fitur kamera dan GPS receiver internal. Mekanisme geotagging photo yaitu pada ketika pengguna mengambil sebuah foto dengan menggunakan ponsel kamera yang memiliki fitur geotagging, kamera pada ponsel akan mencatat informasi/data. Informasi tersebut termasuk waktu dan data ketika sebuah foto diambil, orientasi dari kamera (portrait atau landscape), kordinat GPS latitude dan longitude. Data ini disimpan pada suatu tempat yang disebut EXIF Headers. EXIF (Exchangeable Image File Format) headers berisi petunjuk foto dengan data yang dapat dibaca oleh aplikasi manajemen foto.(Safaat H, 2012)

\section{EXIF Headers}

Data EXIF (Exchangeable Image File Format) merupakan data yang disimpan oleh kamera kedalam sebuah image yang berisi informasi waktu dilakukan pemotretan. EXIF dikembangkan oleh Japanese Electronics Industry Development Association (JEIDA) sebagai upaya untuk mempermudah dan membuat standar pertukaran data antara perangkat lunak pengolah gambar atau citra digital dan perangkat keras seperti kamera, serta didukung oleh hampir seluruh kamera digital.(Mardani, 2014) Informasi umum yang bisa didapatkan dari EXIF sebuah photo adalah tanggal dan jam, merk, tipe kamera, dan jenis lensa yang dipakai untuk memotret foto, resolusi dari kamera, lokasi kordinat GPS latitude dan longitude.

\section{Metode Penelitian}

Metode penelitian yang dibuat dibagi menjadi tiga tahap yaitu yaitu tahap awal atau Tahap I dimulai dari Analisis masalah, tahap kedua atau Tahap II dimulai dari tahap Metode Pengumpulan Data setelah itu tahap Desain dan perancangan sistem dan implementasi sistem dan pada tahap ketiga atau tahap III berupa Testing atau pengujian sistem.(Subli, Sugiantoro, \& Prayudi, 2017)

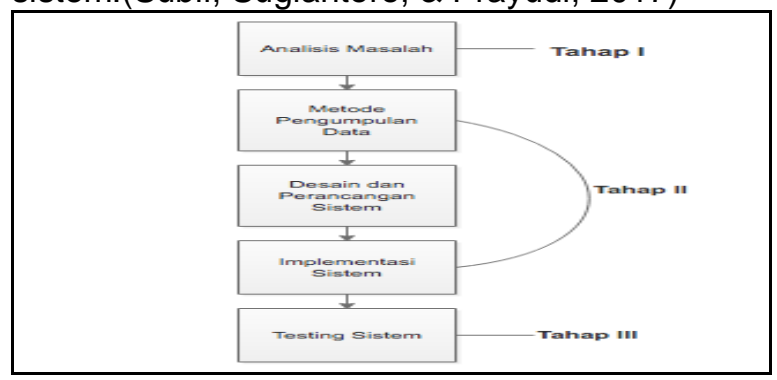

Gambar 1. Metode Penelitian Tracking user Iocation Application 
Pada tahap Metode pengumpulan data pada penelitian ini yaitu tahap dengan melakukan studi literature dan observasi. Studi literatur dilakukan untuk mencari semua informasi yang berkaitan tentang konsep geotagging photo, EXIF data, metadata file, seperti membaca buku-buku, paper atau jurnal-jurnal dan mengunjungi situs-situs yang ada di internet yang berhubungan dengan geotagging photo sedangkan pada observasi dilakukan untuk mendapatkan data secara langsung dengan cara melakukan pengamatan dengan menggunakan alat bantuan menggunakan ponsel.

\section{Implementasi Sistem dan Hasil}

\section{A. Arsitektur Sistem}

Arsitektur sistem merupakan gambaran sistem secara umum pada aplikasi tracker user location. Berikut ini adalah penjelasan dari gambar arsitketur sistem yaitu :

1. Pengguna/user menggunakan ponsel atau smartphone untuk mengambil photo sebuah objek.

2. Pada perangkat ponsel, fitur geotag atau fitur save location info dan GPS dalam kondisi aktif atau ON.

3. Saat photo diambil menggunakan ponsel, melalui fitur GPS akan melakukan request ke satellite untuk mendapatkan informasi kordinat latitude dan longitude.

4. Hasil dari langkah-langkah tersebut menghasilkan sebuah file photo yang memiliki metadata geotagging photo.

5. Setelah dihasilkan file photo, file photo dilakukan analisis metadata dengan menggunakan aplikasi tracking user location v1.0 untuk mendapatkan informasi latitude dan longitude.

6. Apabila terdapat informasi metadata geotagging, maka dilakukan tracking user location.

7. Untuk visualisasi keberadaan user ditampilkan pada Maplnfo.

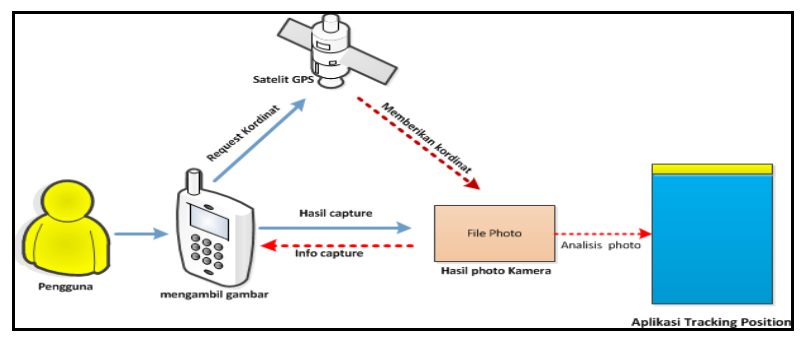

Gambar 2. Arsitektur Aplikasi Tracking user location
B. Perancangan Sistem

1. Flowchart Proses Pencatatan Geotagging Photo

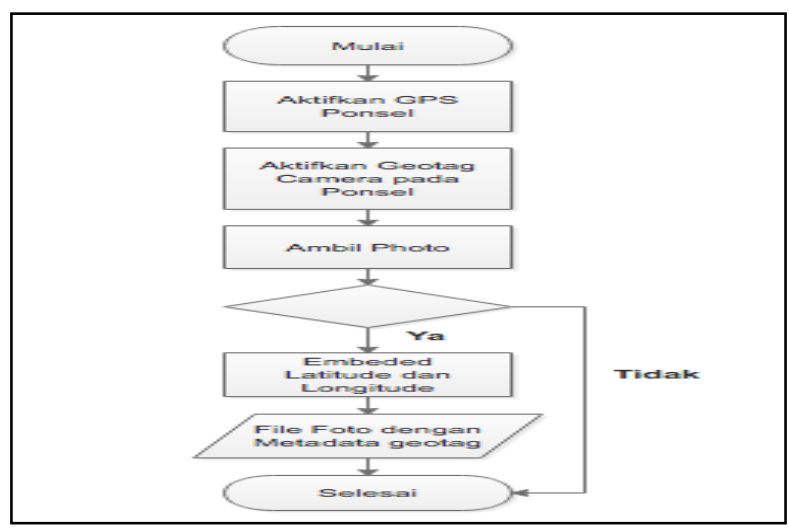

Gambar 3. Flowchart pencatatan geotagging pada photo

Berikut ini adalah penjelasan dari flowchart pada gambar 3 diatas adalah sebagai berikut :

1. Untuk mendapatkan data kordinat latitude dan longitude, GPS pada ponsel harus diaktifkan. Setelah GPS aktif, aktifkan fitur save location info untuk menmbahkan marker pada photo istilahnya yaitu geotagging photo.

2. Pengambilan photo dengan ponsel menghasilkan file photo dengan informasi geotagging yang ddapatkan dari informasi GPS.

\section{Flowchart Proses Tracking user location}

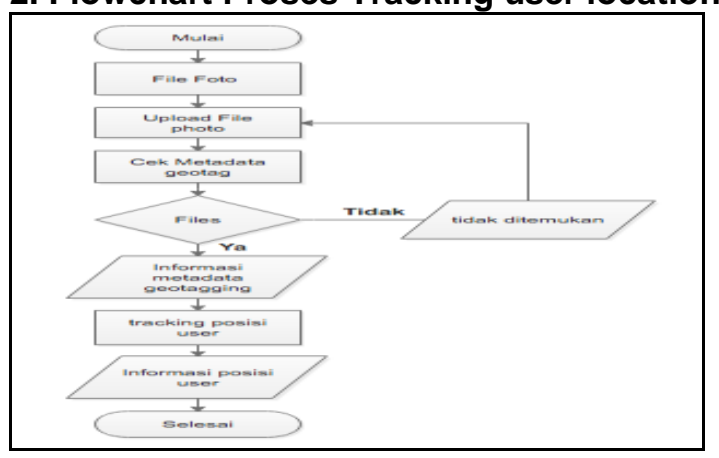

Gambar 4. Flowchart Tracking user location

Berikut penjelasan dari gambar 4 diatas adalah sebagi berikut :

1. Sebelum melakukan tracking user Location, kita harus memiliki file photo yang digunakan didalam mengetahui metadata geotagging photo.

2. File photo diupload pada aplikasi tracking user location untuk mengetahui metadata geotagging pada photo.

3. Photo akan dilakukan pengecekan metadatanya untuk mendapatkan EXIF header datanya. EXIF data header didapatkan 
dari perangkat kamera yang tercatat kedalam file photo.

4. Apabila pengecekan nya berhasil akan didapatkan informasi metadata dari file photo. Metadata berupa geotagging yang berisi informasi kordinat GPS yaitu latitude dan longitude.

5. Kordinat latitude dan longitude didapatkan, informasi tentang keberadaan pengguna bisa diketahui. Pada Map menggunakan Google Map API untuk menampilkan lokasi user di Map.

\section{Use case Diagram Tracking user location}

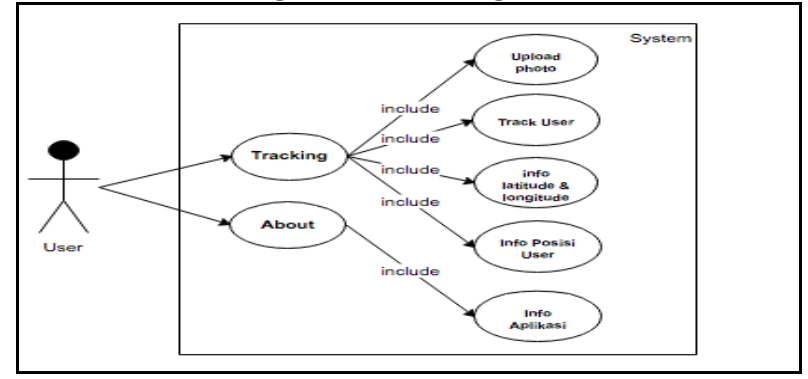

Gambar 5. Use Case Diagram Tracking user Location

Berikut ini adalah deskripsi dari use case diagram pada gambar 5 diatas sebagai berikut :

Tabel 1. Deskripsi Use Case Diagram

\begin{tabular}{|c|l|l|}
\hline No. & Use Case & \multicolumn{1}{|c|}{ Deskripsi } \\
\hline 1. & Tracking & $\begin{array}{l}\text { Menu awal dari aplikasi } \\
\text { apabila user mengakses } \\
\text { aplikasi tracking user location } \\
\text { v1.0. }\end{array}$ \\
\hline 2. & About & $\begin{array}{l}\text { Fasilitas pada sistem tentang } \\
\text { deskripsi aplikasi secara } \\
\text { umum. }\end{array}$ \\
\hline 3. & $\begin{array}{l}\text { Upload } \\
\text { photo }\end{array}$ & $\begin{array}{l}\text { Sistem menyediakan fasilitas } \\
\text { upload photo yang ingin } \\
\text { dianalisa dan tracking lokasi } \\
\text { usertersebut. }\end{array}$ \\
\hline 4. & $\begin{array}{l}\text { Track User } \\
\text { Sistem menyediakan button } \\
\text { untuk melakukan analisa dan } \\
\text { tracking user location dari } \\
\text { media photo. }\end{array}$ \\
\hline 5. & $\begin{array}{l}\text { Info } \\
\text { Latitude } \\
\text { dan } \\
\text { Longitude }\end{array}$ & $\begin{array}{l}\text { Sistem memberikan informasi } \\
\text { kordinat GPS latitude dan } \\
\text { longitude. }\end{array}$ \\
\hline 6. & $\begin{array}{l}\text { Info lokasi } \\
\text { User }\end{array}$ & $\begin{array}{l}\text { Sistem menampilkan lokasi } \\
\text { user dengan marker pada } \\
\text { Map. }\end{array}$ \\
\hline 7. & $\begin{array}{l}\text { Info } \\
\text { Tentang } \\
\text { Aplikasi }\end{array}$ & $\begin{array}{l}\text { Sistem } \\
\text { informasi tentang aplikasi } \\
\text { secara umum. }\end{array}$ \\
\hline
\end{tabular}

\section{Implementasi Sistem}

\section{Antarmuka Aplikasi}

Aplikasi Tracking user location v1.0 merupakan aplikasi berbasis web yang dibangun menggunakan bahasa pemrograman HTML dan PHP. Pada aplikasi ini memiliki 2 (dua) menu yaitu menu Tracking dan About. Berikut ini adalah antarmuka aplikasinya :

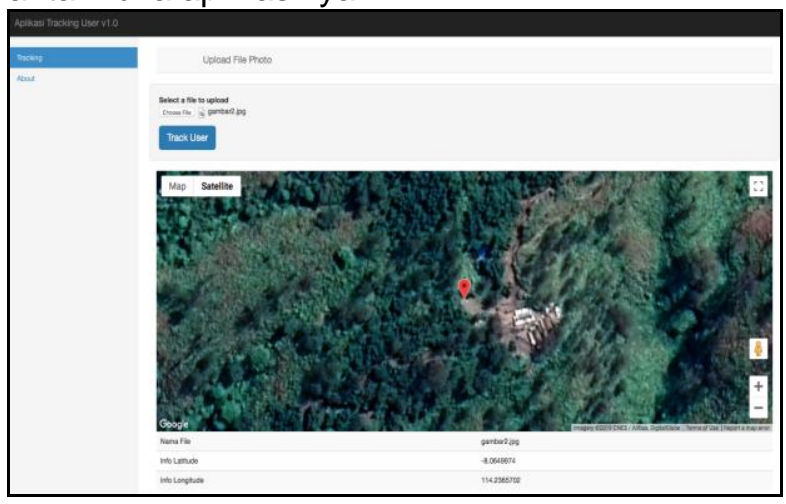

Gambar 6. Antarmuka Aplikasi Tracking user location v1.0

Aplikasi Tracking user location menampilkan lokasi user dengan visualisasi menggunakan Google Map API. Pada Map lokasi kordinat pengguna yang ditemukan ditampilkan dengan menggunakan penanda berupa marker. Posisi kordinat didapatkan dari penambahan latitude dan longitude GPS kedalam file photo yang diambil menggunakan ponsel. File photo yang akan dianalisis atau digunakan untuk tracking user location didalam mencari keberadaan atau history keberadaan pengguna. Metadata geotagging pada photo terdapat informasi latitude dan longitude, untuk menghasilkan informasi tersebut kondisi GPS dan Save Location Info di fitur kamera dalam keadaan aktif. Untuk mendapatkan informasi lokasi pengguna, terlebih dahulu dilakukan pengecekan metadata geotagging pada file photo. File photo bisa didapatkan dari ponsel secara langsung yang ingin ditracking lokasinya. Apabila metadata geotagging ditemukan didalam file photo, marker pada Map akan langsung muncul.

\section{Kebutuhan hardware}

Untuk menjalankan aplikasi Tracking user location dibutuhkan spesifikasi minimum perangkat keras sebagai berikut ini :

a. Processor Intel(R) Core 2 Duo.

b. RAM 2 GB

c. OS Windows 7

d. HD $500 \mathrm{~GB}$

e. VGA on Board

f. PCI LAN Card 


\section{Kebutuhan Software}

Adapun kebutuhan perangkat lunak untuk kebutuhan aplikasi tracking user location adalah sebagai berikut :

a. Browser chrome

b. Aplikasi XAMPP (Apache)

c. PHP v 5.5.38

d. Text editor Notepad++

\section{Pembahasan}

Aplikasi tracking user location digunakan untuk melakukan tracking atau pencarian keberadaan pengguna/user berbasis web. Untuk mendapatkan lokasi pengguna/user menggunakan media digital berupa photo yang diambil dari ponsel. Pada Aplikasi tracking user location ini menggunakan photo yang diambil dengan ponsel yang memiliki fitur kamera dan GPS. Berikut ini adalah metadata dari file photo yang didapatkan informasinya dengan tools online https://www.get-metadata.com sebagai berikut :

Tabel 2. Tabel informasi Metadata file photo

\begin{tabular}{|c|l|l|}
\hline No & Nama File & \multicolumn{1}{|c|}{ Info Metadata } \\
\hline 1. & Gambar2.jpg & File Name : gambar2.jpg \\
& & File Size : 4.7 MB \\
& & File Modify Date : \\
& 2019:01:07 08:05:51+01:00 \\
& File Type : JPEG \\
& Make : XIAOMI \\
& Gps Altitude : 2237.7 m \\
& Above Sea Level \\
& Gps Date Time : 2017:12:24 \\
& 23:51:38Z \\
& Gps Latitude : 8 deg 3' \\
& 53.99" N \\
& Gps Longitude : 114 deg 14' \\
& $11.65 "$ E \\
& Gps Position : 8 deg 3' \\
& $53.99 "$ N, 114 deg 14' 11.65" \\
& E \\
\hline
\end{tabular}

Dari informasi metadata diatas berikutnya dilakukan analisis dengan menggunakan aplikasi tracking user location v1.0 untuk mendapatkan informasi lokasi pengguna dengan menggunakan media photo sebagai parameter dan dengan visualisasi Map dengan menggunakan Google Map API untuk mengetahui lokasi user berada dimana saat photo itu diambil. Berikut tampilan aplikasinya :

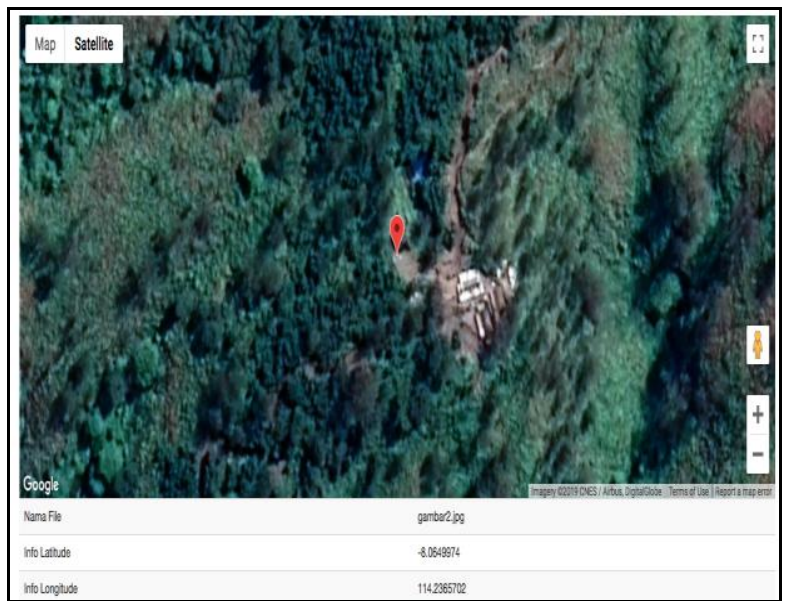

Gambar 7. Tampilan Map Info Aplikasi Tracking user location

Dari tampilan gambar 7 diatas didapatkan informasi tentang lokasi user dari aplikasi tracking user location. Lokasi user ditampilkan dengan tanda marker warna merah pada Map. Informasi metadata geotagging photo dengan aplikasi tracking user location didapatkan data latitude : 8.0649974 dan data longitude : 114.2365702 .

\section{E. Pengujian}

Pada tahap pengujian menggunakan metode blackbox testing. Pengujian dilakukan untuk menguji fungsionalitas dari aplikasi yang sudah dibuat. Didalam pengujian aplikasi menggunakan blackbox testing dengan sample testing yang menggunakan data yang dipilih dengan spesifikasi data tertentu. Adapun hasil pengujian aplikasi secara fungsionalitas didapatkan informasi sebagai berikut :

Tabel 3. Tabel Uji fungsionalitas aplikasi

\begin{tabular}{|l|l|l|c|}
\hline No & \multicolumn{1}{|c|}{$\begin{array}{c}\text { Point } \\
\text { Pengujian }\end{array}$} & \multicolumn{1}{|c|}{ Keterangan } & $\begin{array}{c}\text { Hasil } \\
\text { Testing }\end{array}$ \\
\hline 1. & Upload File & $\begin{array}{l}\text { Befungsi untuk } \\
\text { Upload file photo } \\
\text { kedalam sistem, } \\
\text { dimana file photo } \\
\text { yang diupload } \\
\text { akan dilakukan } \\
\text { analisis. }\end{array}$ & Sesuai \\
\hline 2. & $\begin{array}{l}\text { Analisis } \\
\text { Metadata }\end{array}$ & $\begin{array}{l}\text { Berfungsi untuk } \\
\text { mengambil } \\
\text { informasi } \\
\text { geotagging pada } \\
\text { photo dan } \\
\text { menampilkannya } \\
\text { berupa informasi } \\
\text { kordinat latitude } \\
\text { dan longitude. }\end{array}$ & Sesuai \\
\hline 3. & Tracking & Menampilkan & Sesuai \\
\hline
\end{tabular}




\begin{tabular}{|l|l|l|}
\hline user & informasi \\
location & $\begin{array}{l}\text { keberadaan user } \\
\text { melalui fitur map } \\
\text { dengan } \\
\text { memberikan } \\
\text { tanda berupa } \\
\text { marker. }\end{array}$ \\
\end{tabular}

Tabel 4. Tabel Uji sample testing dengan spesifikasi data

\begin{tabular}{|c|c|c|c|}
\hline No & $\begin{array}{c}\text { Perangakat } \\
\text { Ponsel }\end{array}$ & $\begin{array}{c}\text { Metdata } \\
\text { Geotagging }\end{array}$ & Keterangan \\
\hline 1. & Xiaomi Mi5 & $\begin{array}{l}\text { Nama File : } \\
\text { photo_1.jpg } \\
\text { Info } \\
\text { Latitude: } \\
8.6731788 \\
\text { Info } \\
\text { Longitude : } \\
\text { 115.226716 }\end{array}$ & $\begin{array}{l}\text { Menampilkan } \\
\text { informasi } \\
\text { data kordinat } \\
\text { serta lokasi } \\
\text { user di Map. }\end{array}$ \\
\hline 2. & Iphone 6 & $\begin{array}{l}\text { Nama File : } \\
\text { photo_2.jpg } \\
\text { Info } \\
\text { Latitude: } 0 \\
\text { Info } \\
\text { Longitude : } \\
0\end{array}$ & $\begin{array}{l}\text { Tidak } \\
\text { didapatkan } \\
\text { informasi } \\
\text { mengenai } \\
\text { data } \\
\text { geotagging } \\
\text { pada file } \\
\text { photo. }\end{array}$ \\
\hline 3. & Samsung & $\begin{array}{l}\text { Nama File : } \\
\text { photo_3.jpg } \\
\text { Info } \\
\text { Latitude: } 0 \\
\text { Info } \\
\text { Longitude : } \\
0\end{array}$ & $\begin{array}{l}\text { Tidak } \\
\text { didapatkan } \\
\text { informasi } \\
\text { mengenai } \\
\text { data } \\
\text { geotagging } \\
\text { pada file } \\
\text { photo. }\end{array}$ \\
\hline
\end{tabular}

Dari hasil pengujian dari sisi fungsionalitas pada tabel 3, didapatkan hasil aplikasi berjalan dengan baik tanpa ada hambatan dan sesuai dengan output dari aplikasi yang dibuat. Sedangkan pada pengujian uji sample testing dengan menggunakan spesifikasi data berupa perbandingan hasil photo dari beberapa perangkat yang berbeda. Dari tiga jenis file photo yang digunakan dari perangkat yang berebeda, didapatkan ponsel xiaomi Mi5 yang bisa dibaca data geotagging photo dari aplikasi tracking user location dibandingkan jenis ponsel Samsung dan Iphone 6.

\section{Kesimpulan}

Adapun kesimpulan dari penelitian yang berjudul Tracking user location Location dengan
Menggunakan Geotagging pada Metadata Photo adalah sebagai berikut :

1. Aplikasi tracking user location v1.0 yang berhasil dibangun dapat membantu pengguna baik praktisi maupun masyarakat luas didalam melakukan pelacakan keberadaan user dari media photo.

2. Pada aplikasi tracking user location v1.0 sudah berhasil melakukan tracking user location dan menampilkan informasinya secara visualisasi di Map.

3. Aplikasi tracking user location v1.0 selain menampilkan lokasi pengguna, aplikasi ini sudah mampu menampilkan informasi metadata geotagging pada photo.

4. Dari hasil pengujian dengan menggunakan metode blackbox testing dari sisi fungsionalitas didapatkan hasil aplikasi berjalan dengan baik tanpa hambatan sedangkan dari sisi sample testing data menggunakan tiga photo dari perangkat tiga ponsel yang berbeda didapatkan hasil hanya ponsel dengan merk Xiaomi yang bisa dianalisa untuk mendapatkan informasi geotagging photo.

\section{Pustaka}

Bandung, J. D. (n.d.). PELAPORAN PELAYANAN PUBLIK BERBASIS ANDROID Teknik Informatika - Universitas Komputer Indonesia.

Mardani, A. (2014). Sistem Informasi Geografis Pelaporan Masyarakat (SIGMA) Berbasis Foto Geotag. Jurnal Sistem Dan Teknologi Informasi (JustIN), 3(Vol 3, No 1 (2014)).

Nur, G., Handayani, P., \& Sudarsa, Y. (2017). Sistem Keamanan Kendaraan Bermotor dengan Pengambilan Citra Satelit dan GPS Berbasis Aplikasi Mobile, 617-620.

Safaat H, N. (2012). Pemrograman Aplikasi Mobile Smartphone dan Tablet PC Berbasis Android. Bandung.

Subli, M., Sugiantoro, B., \& Prayudi, Y. (2017). METADATA FORENSIK UNTUK MENDUKUNG PROSES INVESTIGASI DIGITAL. Jurnal IImiah DASI, 18, 44-50.

Zaenudin, Sugiantoro, B., \& Prayudi, Y. (2018). Correlation Analysis Of Forensic Metadata For Digital Evidence. International Journal of Computer Science and Information Security (IJCSIS), 16(3), 85-89. 